\title{
Perceptions of Drug Use in The Workplace
}

\author{
Debra Charles* and Maciej Ferenc \\ Department of Psychology, University of Miami, USA
}

*Corresponding author: Debra Charles, Department of Psychology, University of Miami, Florida, PO Box 258184, FL 33124-0751, 305-284-1566, USA.

Received Date: March 12, 2020

Published Date: April 15, 2020

\section{Abstract}

Given the ongoing conversation regarding the national legalization of cannabis, it is important to understand perceptions of the use of cannabisrelated substances. In the current study, we collected data from 197 adults via an online survey to examine moral perceptions about drug use in general and in the workplace. Specifically, we asked subjects to report whether testing positive for a given substance was sufficient grounds for being fired when that substance was prescribed by a doctor or when taken independent of a physician. Our results indicate that adults view use of marijuana, specifically CBD, in a similar a manner as use of Tylenol or Motrin in the workplace. Indeed, an equal percentage of subjectsapproximately 83\%--reported that it was wrong to fire an employee for testing positive for Tylenol or for CBD. We discuss the implications of our findings.

\section{Introduction}

Recent work has started to examine perceptions and effects of substance use in the workplace [1-4]. A gap in this literature relates to the moral perceptions people hold regarding the use of various substances in the workplace. Whereas certain types of drugs might be regarded as acceptable (e.g., ibuprofen), others might not (e.g., opioids). Given the epidemic associated with opioid abuse, researchers have become interested in the extent to which other, substances (e.g., cannabinoids), might serve to replace more highly addictive narcotics [5]. Indeed, cannabis less harmful has a long history of being used medicinally [6]. But to the extent substances, like cannabinoid products, and their users are stigmatized, it might be more difficult to change medical norms. Here we examine perceptions of how morally wrong it is to use various substances in the workplace both under medical advisement and under conditions of self-medication. Specifically, we explore perceptions of how appropriate it would be to fire an employee based on either doctor-directed or self-directed substance use in the workplace.

\section{Methods}

\section{Participants}

197 participants (127 males; 70 females) completed an online survey on cannabis usage (age range: 20-68; $\mathrm{M}=33.48, \mathrm{SD}=8.94$ ). Participants identified as White (54.3\%), African American (5.1\%), Hispanic/Latino (6.1\%), Asian (33.5\%), and/or Native American, Alaskan Native (1.0\%). Participants were paid $\$ 1.00$ for completing a survey that took on average approximately 8 minutes to complete (range: 133s-4732s; M=471.39s; SD=419.75s). Local IRB approval was obtained.

\section{Materials and Procedure}

Participants were recruited using Amazon's Mechanical Turk. After reading and agreeing to the consent form, participants responded to questions regarding their perceptions of use of various substances as medically prescribed or not. Upon completion, participants were supplied with a survey code to use for participation payment via Amazon's Mechanical Turk.

\section{Results}

We report on usage statistics of various substances in our sample in Table 1. As can be seen, large proportions of subjects reported using each kind of substance. Next we evaluated subjects' reports of how morally wrong it is to take each type of substance without a prescription. For each substance that was not medically prescribed, we asked subjects to respond whether taking the substance was morally wrong on the following scale: $1=$ "not morally wrong"; 2="somewhat morally wrong"; or 3= "extremely morally wrong". As shown in Table 1, subjects reported taking Tylenol and Motrin without a prescription as least morally, followed by taking cannabinoid products without a prescription. Taking morphine without a prescription was views as the most morally wrong of all the substances. Last, we asked subjects to image two scenarios. One 
in which a co-worker tested positive for a drug he was taking with a doctor's prescription and was subsequently fired and another scenario in which a co-worker tested positive for a drug he was taking without a doctor's prescription and was subsequently fired. The scenarios were as follows: Prescription: "An acquaintance, who works a 9-5 office job, recently underwent back surgery to help reduce chronic nerve pain. The surgery was a success, but left him in sporadic pain, which he was told would subside after a few months. To manage his pain, the doctor prescribed him medication, which he started to take. Upon returning to work, he was asked to take a routine drug test. Results from his urine sample revealed trace amounts of the drug his doctor prescribed, which ultimately lead his boss to fire him."

No prescription: "Now, imagine your colleague had the same back surgery with the same post-surgery pain, but that his doctor

Table 1: Descriptive statistics. had not prescribed any medication. His doctor thought it was better to "feel the body's signals of pain". However, your colleague found the pain unbearable and took some medication, which was discovered in his urine during his workplace drug test. He was then fired. "We then asked if it was okay for the coworker to be fired if the substance was either Tylenol, Motrin, Codeine, Vicodin, Percocet, Morphine, street bought marijuana, over the counter CBD vapes or tinctures, physician recommended legal marijuana, physician recommended legal CBD/ THC tinctures, alcohol, or Xanax.

As reported in Table 1, we found that overall, it was more acceptable to fire an employee for using a substance without a medical prescription. Also, the substances viewed as justifying termination the most were Percocet, street bought marijuana, and alcohol.

\begin{tabular}{|c|c|c|c|}
\hline Substance & $\begin{array}{c}\text { Percent of subjects } \\
\text { reporting use }\end{array}$ & $\begin{array}{c}\text { How wrong to use without a } \\
\text { prescription Mean (SD) }\end{array}$ & $\begin{array}{c}\text { Percent indicating 0K to fire employee } \\
\text { for failing drug test Rx (no Rx) }\end{array}$ \\
\hline Tylenol & 77.5 & $1.40(.65)$ & $17.3(16.8)$ \\
\hline Motrin & 55.8 & $1.46(.74)$ & $8.6(10.7)$ \\
\hline Codeine & 47.9 & $1.91(.75)$ & $13.7(29.1)$ \\
\hline Vicodin & 30.3 & $1.92(.74)$ & $10.7(28.6)$ \\
\hline Percocet & 32.5 & $1.87(.71)$ & $17.8(35.5)$ \\
\hline Xanax & 31.3 & $1.93(.76)$ & $10.2(27.9)$ \\
\hline Morphine & 27.1 & $2.09(.83)$ & $11.7(31.0)$ \\
\hline Street-bought marijuana & 52.3 & $1.63(.77)$ & $18.8(32.5)$ \\
\hline OTC CBD vapes or tinctures & 34 & $1.68(.82)$ & $14.2(19.8)$ \\
\hline Medically prescribed marijuana & 23.1 & -- & $14.7(24.0)$ \\
\hline Medically prescribed CBD/THC & 16 & -- & $10.2(16.8)$ \\
\hline Alcohol & 75.4 & -- & $25.9(32.5)$ \\
\hline
\end{tabular}

\section{Discussion}

In this study, we examined perceptions of the morality of the use of various substances as well as whether different substances are differentially perceived to justify job termination. Despite the large proportion of subjects reporting the use of street bought marijuana, the perception appears to be that its use in the workplace justifies termination similar to other schedule 1 narcotics. If the medical establishment aims to supplement or replace opioid substances with plant based palliative medicines like cannabinoids, there is much work to be done in terms of public perception. The data here contribute to this area of growing research.

\section{Acknowledgement}

None.

\section{Conflict of interest}

Author declare no conflict of interest.

\section{References}

1. Frone MR (2009) Does a permissive workplace substance use climate affect employees who do not use alcohol and drugs at work? A U.S. National study. Psychol Addict Behav 23(2): 386-390.

2. Frone MR (2012) Workplace substance use climate: Prevalence and distribution in the US Workforce. J Subst Use 17(1): 72-83.

3. Keith DR, Gunderson EW, Haney M, Foltin RW, Hart CL (2017) Smoked marijuana attenuates performance and mood disruptions during simulated night shift work. Drug Alcohol Depend 178: 534-543.

4. Roberts S, Fallon LF (2001) Administrative issues related to addition in the workplace. Occupational Medicine 16(3): 509-515.

5. Jose A, Thomas L, Baburaj G, Munisamy M, Rao M (2020) Cannabinoids as an alternative option for conventional analgesics in cancer pain management: A pharmacogenomics perspective. Indian J Palliat Care 26 (1): 129-133.

6. Zuardi AW (2006) History of cannabis as a medicine: a review. Braz J Psychiatry 28(2): 153-157. 